\title{
Testing and Assessment of Marble and Limestone (TEAM)- Important Results from a Large European Research Project on Cladding Panels
}

\begin{abstract}
The use of natural stone as facade cladding has been shown to have much lower life cycle costs and they are more environmentally friendly than comparable products of concrete, glass, and steel. Promoting the use of natural stone has therefore a great positive impact on the environment. However, the number of occurrences of bowing and expansion of marble and limestone panels has led to increased maintenance costs, significant safety risk, and negative publicity. The lack of knowledge of a solution to the problem of bowing marble has a large negative effect on the entire stone trade. In response, short-sighted and less durable construction solutions are used as an alternative, adding to the decreasing export figures and numbers of employees within the stone sector. The TEAM (TEAM=TEsting and Assessment of Marble and limestone) project addresses a problem with marble types, from several European countries, that display bowing on facades in both cold and warm climates. There is, therefore a need to develop harmonized European standards for differentiating between marble that is susceptible to bowing and marble that is not. Resolution No. 013, in May 1999 taken by the European Committee for Standardization (CEN), Technical Committee (TC) 246 Natural Stone states the urgent needs "to develop a direct test method of the bowing risk for marble cladding products." Thus, the project addresses the mandate for external wall coverings and the safety of panels. This paper serves to give a comprehensive overview of the main findings in the project. The main objectives were: - To understand and explain the mechanisms of the expansion and loss of strength, probably the most important phenomena leading to degradation of marble and limestone clad facades. - To prevent the use of deleterious marble and limestone by introducing drafts for European standards. - To develop a concept for assessment of facades, including a monitoring system in order to predict strength development and improve safety and reliability. $\bullet$ To analyze if surface coating and impregnation could prevent or diminish the degradation. $\bullet$ To address quality control aspects in order to optimize the production conditions. The TEAM project consortium, representing nine EU (European union) countries, comprised sixteen partners representing stone producers and trade associations, testing laboratories, standardization and certification bodies, consultants, building owners and caretakers and producers of fixing and repair systems. A state-of-the-art report has been written and is based on an extensive compilation of more than 400 papers on marble and limestone deterioration dating from the late 1800 s to 2006. A survey of about 200 buildings has given a clear picture of the extent of the problem in geographical, geological, and climatological terms. Detailed case studies of six buildings have resulted in a methodology for assessment of facades including monitoring system and risk assessment. Research both in the laboratory and the field were performed on a large number of different stone types from different countries and used in different climates. This gave the explanation of degradation mechanisms and led to the determination of the critical influencing factors. Two tests methods, including precision statements: one for bowing [1] and one for thermal and moisture irreversible expansion have been prepared for submission to CEN TC 246. Repair techniques based on the use of surface coating and impregnation systems has been tested at laboratory and in the field. Positive side effects including increased durability and easier cleaning have been observed. Guidelines for production and product control have been proposed, and an instruction for stone sampling and description has been developed.
\end{abstract}

\section{Introduction}

The TEAM project is by far the largest European R\&D project ever directed towards natural stones used for building applications. It has focused on the problem of expanding and bowing marble and expanding limestone cladding for outdoor uses. The main problem with unsuitable stone types is failure at anchoring points and the decrease of strength over time that is always associated with the bowing expansion, or both.

Manuscript received October 17, 2006; accepted for publication May 2, 2007; published online June 2007. Presented at ASTM Symposium on Dimension Stone Use in Building Construction on 31 October 2007 in Tampa, FL; K. Hoigard and M. Scheffler, Guest Editors.

${ }^{1}$ SP, Technical Research Institute of Sweden, Box 857, 50115 Borås, Sweden

${ }^{2}$ RAMBOLL A/S, Bredevej 2, 2830 Virum, Denmark 
The basis for the project results are, in addition to personal knowledge, a literature review of more than 400 articles, a survey of about 200 buildings, and a comprehensive program of laboratory and field work. The project has rendered numerous findings that are useful for stakeholders such as the stone industry, European standardization, testing and research organizations, building owners, consultants, and architects. The most important ones are discussed below.

The project started in March 2000 and ended in August 2005 and has had sixteen partners from nine different countries and a budget of about 5 million U.S. partly financed by the European Commission. The problems are clearly of interdisciplinary character, while the project engaged experts from all parties concerned, e.g., stone producers, trade associations, standardization bodies, building owners, consultants, testing and research laboratories, universities, and caretakers and producers of anchoring systems, surface treatments, and repair systems.

\section{Project Elements/Work Packages (WP)}

\section{Literature Study-WP 1}

The starting point of the project was a literature study aiming at collecting and evaluating more than 100 years of research relating to this specific problem. The existing hypotheses were compiled and evaluated and many of them tested in the laboratory phase of the project.

Some of the most common hypotheses/statements were:

- Fine-grained marble is good or bad (both statements occur) [2-5].

- Carrara marble is bad.

- Acid rain and pollution are the reasons for the problems.

- Frost action is the cause and marble should not be used in the "far north" e.g., in Finland.

- Marble with a specific range in strength is suitable [6].

- Anisotropic thermal expansion of calcite and dolomite causes granular de-cohesion [4,7].

- The influence of moisture (and possibly free water) and temperature variations are crucial [8].

- The release of locked-in rock stresses is important.

- A complex microstructure is favorable [5,6,9-13].

The only hypotheses generally valid are numbers 7 and 9. Number 6 contributes to the problem. However, without the presence of water/moisture the order of magnitude of degradation is quite small.

It has become very clear, through the findings of the project, that the major influencing parameters are thermal expansion in a wet condition and the microstructure of the marble. See more under Section II E below. A comprehensive literature review has been carried out and is also included in this special volume [14].

\section{Survey of Stone Projects-WP 1}

In parallel to the literature survey, about 200 buildings using natural stone were identified, mostly in Europe (Fig. 1), but also in other parts of the world [15]. Most of these buildings were clad with marble (both "good" and "bad" performing) and limestone. It has provided a unique opportunity to study and test many of the hypotheses on real buildings and not just in the laboratory. This has given us knowledge of the extent of the problem, both geographically and geologically. Suitable marble types can survive for many years in any climate (e.g., more than 100 years). It is equally clear that unsuitable marble comes from many countries all over the world. The building owners also provided TEAM with the possibility to continue with detailed studies on a few of them. The geographical, geological, and climatic spread of the 200 buildings is representative for all of Europe!

\section{Detailed Cases Studies-WP 2}

Six of the two hundred buildings were chosen for detailed studies. These buildings represent different climates and marble types: Danish National Bank in Copenhagen (DK), City Hall in Nyköping (SE), City Hall in Malmö (SE), Magenta Hospital in Turin (IT), University Theologicum in Göttingen (DE), and St. Marien Hospital in Lünen (DE) $[7,15,16]$. A special piece of equipment (the bow-meter) which can be used for high precision and repeatable measurements of the bowing magnitude of the panels has been devel- 


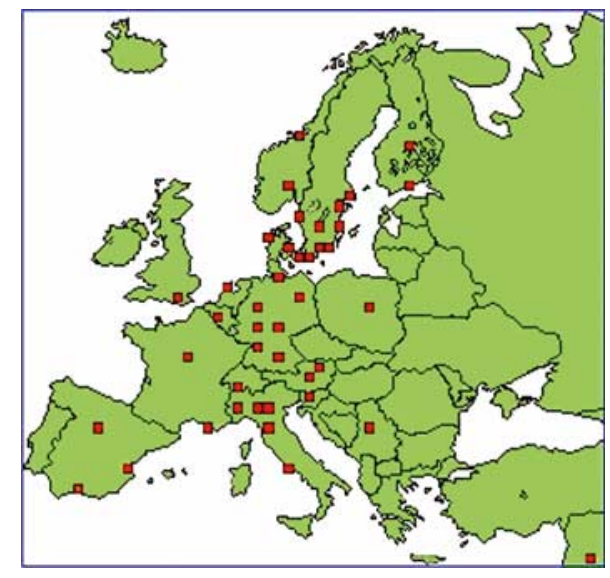

FIG. 1-Distribution of buildings in Europe, where bowing or distortion of the marble cladding has been recorded by the TEAM partners.

oped. In addition to the parameters listed below, the influence on the bowing of the design, the anchoring system, the building physics (like ventilation and insulation), façade orientation, etc., were studied. The studied parameters included:

- Height above the ground.

- Climatic conditions, including microclimate.

- Cracks and breakouts in panels.

- Cladding design.

- Anchoring system.

- Dimension and thickness of panels.

- Open or closed joints.

- Width of the joints.

- Fabric/orientation of foliation of the stone.

- Convex or concave bowing.

- Surface finishing and surface treatment.

The detailed study of these six buildings, the approximately 200 buildings surveyed and the literature review led to the final selection of the marble types for the major laboratory research work in WP 5. A methodology for site investigations and also for sampling was developed. By including the results of WP 5 and WP 7 it has been possible also to give recommendations for remedial actions. One of them is to minimize the influence of water by applying a suitable surface treatment. The development of the laboratory bow-test (described later in this article) has clearly shown that each marble and building is unique. Every marble has its unique degradation curve (Fig. 2). The actual buildings and marble types are given in TEAM Final Technical report and Ref. [14]. Any prediction of the remaining service life for a specific building has, therefore, to be developed individually and depends on the specific marble type in combination with the microclimate (especially surface temperature variations).

The influence of different anchoring systems was checked and it could be concluded that there is no significant influence on the bowing phenomena as such. However, mortized panels seem to have a lower tendency to bow. This may be due to the smaller temperature gradient developed in such a construction. This observation was supported by monitoring on a test wall installed in Waldactahl, SW Germany (Fig. 3). In addition, the fischerwerke system with undercut anchors can also be recommended since it requires less strength to keep the panels in place compared to kerbs or pins/dowels.

\section{Long-term Monitoring-WP 3}

In addition to the test wall at fischerwerke, monitoring equipment was installed on three of the six buildings mentioned above. The following parameters were monitored:

- surface temperature on the external surface of the stone

- time-of-wetness/condensation on external surface of the stone

- strain in two directions on the external surface of the stone 
Loss in bending strength versus time

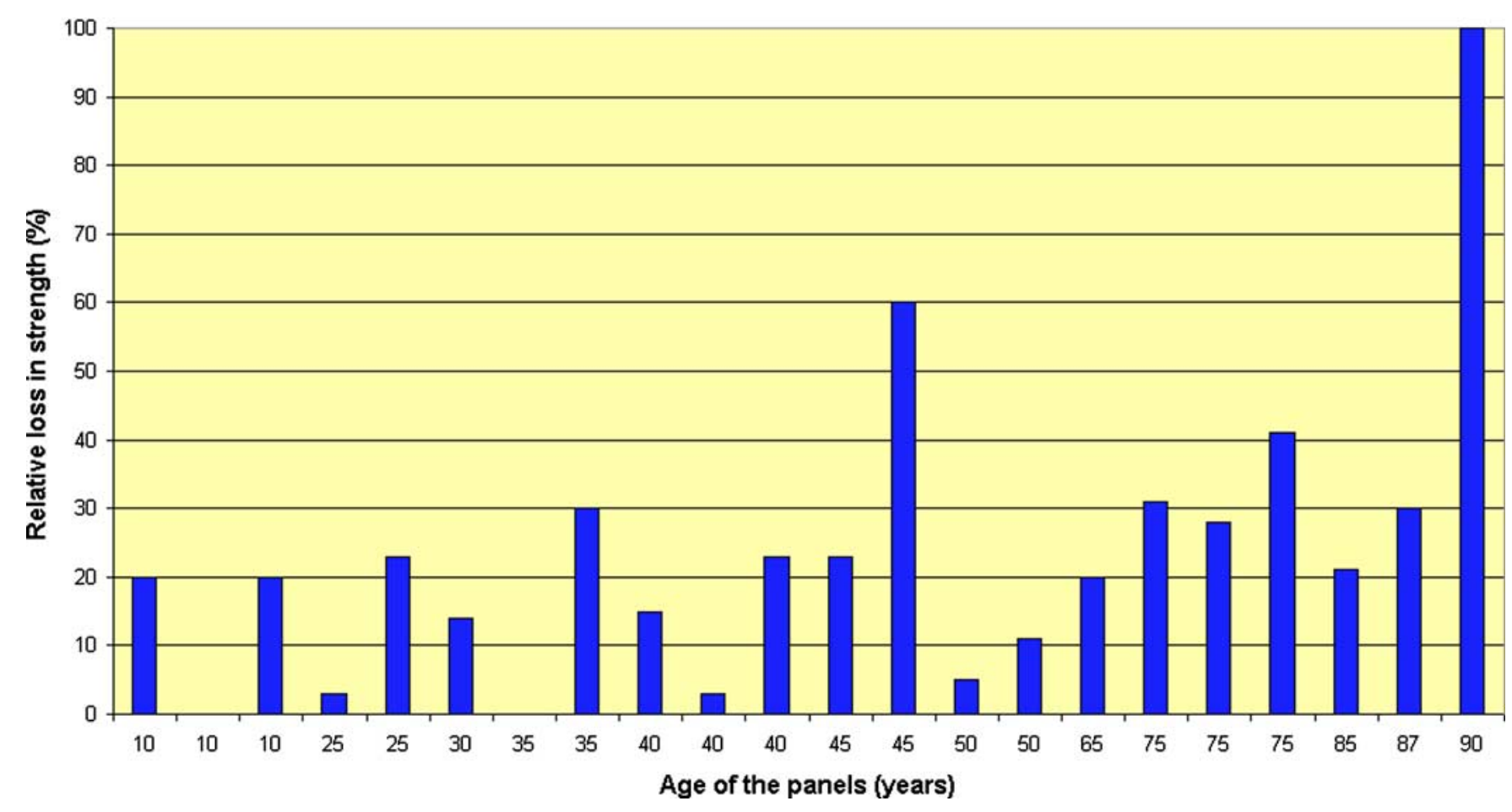

FIG. 2-The relative loss in flexural strength, and modulus of rupture, recorded from different marble clad buildings. The initial strength values are generally data provided by the producer.

- surface temperature on the internal surface of the stone

- air temperature in the gap behind the panel

- relative humidity in the gap behind the panel

- time-of-wetness/condensation on internal surface of the stone

- strain in two directions on the internal surface of the stone

- shade air temperature

- shade relative humidity

The bowing magnitude was measured four times a year with the bow-meter and correlated with the strain measurements. The monitoring has mainly generated input to the definition of the laboratory bowtest and the wet-expansion test and a greater understanding of the diurnal variations in temperature of the panels. By filtering these small scale changes it has been possible to establish a very good correlation between measurements of long-term residual strain and the manual measurements of the bowing magnitude with the bow-meter. A very important finding is that manual measurement on one occasion by use of, e.g., the bow-meter will provide almost random values due to the diurnal changes that can be up to $2 \mathrm{~mm} / \mathrm{m}$. Measurements of the bowing magnitude therefore has to be done on repeated occasions under similar conditions!

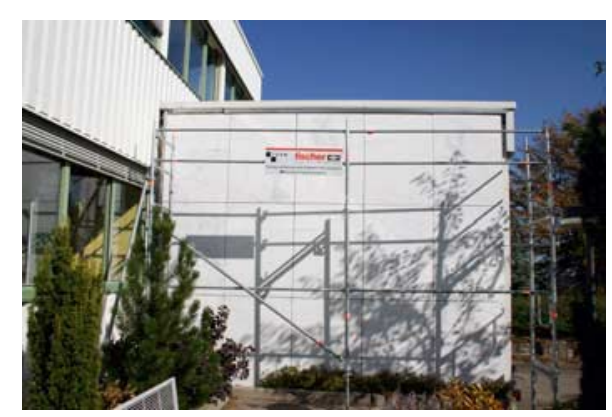

FIG. 3-Test wall at fischerwerke in Waldactahl, SW Germany. One marble type in combination with five different anchoring systems were installed. 


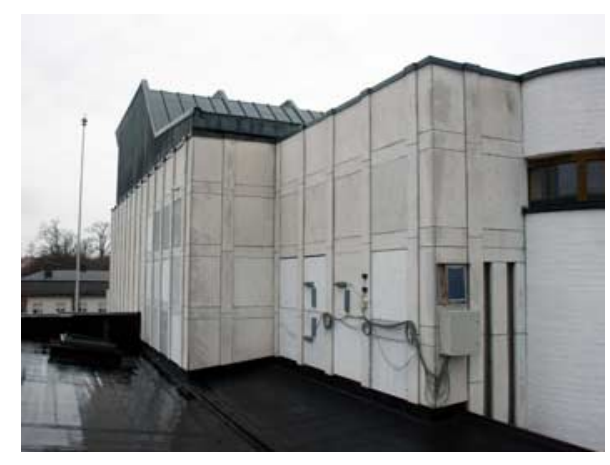

FIG. 4-Test site at the city hall of Nyköping. Different marble, different thickness, and chemical treatments are tested together with monitoring of temperature and strain.

At one location the monitoring has been combined with an in situ test wall of different marble types, thicknesses, and chemical treatments (Fig. 4). See also Section II H below.

One very important deliverable from the combined work of monitoring, field inspection, and field exposure is the development of a methodology for risk assessment. The methodology includes the combination of results from laboratory tests and in situ nondestructive testing to enable a prediction of the remaining service life of existing panels.

\section{Sampling and Influencing Parameters-WP 4}

The case studies of buildings with suitable and unsuitable marble provided most of the input for the selection of marble types to include in the major laboratory research program. It was impossible to be completely sure of the exact quarry location for the marble on every building due to incomplete documentation. In total, 16 quarries have been sampled, giving 17 varieties of carbonate rock types. The samples represent 3 pure dolomite marbles, 11 pure calcite marbles, 1 ophicalcitic marble (containing serpentine), 1 limestone, and 1 silicate rich, contact metamorphic limestone. In addition, 86 marble types were sampled on different occasions at exhibitions, fairs, etc. See Table 1 below. These samples were used in the laboratory bow-test for evaluating the bowing potential and provided the additional necessary samples in order to ensure a broad geological spread of marble types in the laboratory test program.

The possible influence of quarrying and productions processes, together with geological aspects, were assessed in order to include such variables in the samples and at the same time increase the possibilities of explaining the test results. Detailed sampling and sample marking instructions were developed in order to ensure full traceability of all laboratory samples. Very few of the marble types had a visually observable foliation and these were sampled with respect to that in order to enable the assessment of this parameter's influence on the test results.

TABLE 1-The origin of screening tested fresh samples.

\begin{tabular}{lc}
\hline \multicolumn{1}{c}{ Country } & No. of Samples \\
\hline Italy & 36 \\
Greece & 10 \\
Portugal & 13 \\
Sweden & 8 \\
Norway & 7 \\
Greenland & 1 \\
Turkey & 1 \\
Bulgaria & 1 \\
France & 1 \\
USA & 1 \\
Macedonia & 5 \\
Germany & 1 \\
Spain & 1 \\
Schweiz & 1 \\
Austria & 1 \\
Total: & 2 \\
\hline
\end{tabular}




\section{Full Scale Laboratory Testing, Including Quarry and Processing Variables-WP 5}

Rock stress measurements were carried out in three quarries in the Carrara area. The original hypothesis for the rock stress measurements was that we would expect high stresses or a high anisotropic stress pattern in areas where strong bowing material is extracted and low stresses in localities where the quarried marble has not shown problems with bowing. The in-situ stress measurements clearly indicate that the marble in all test sites is subject to quite high, nongravitational stresses. The stresses are probably a combination of locked-in residual stresses and tectonic stresses. The results of the actual rock stress measurements show that our original hypothesis was somewhat simplified. High stresses are measured in all marbles, even in the two marbles where no bowing have been experienced. For these two quarries, it seems that the stresses are released during block extraction, which is not the case in the quarry where they have experienced bowing marble. In addition, some rock mechanical properties (Young's modulus and sonic velocity) of the bowing marble are much lower than the other two.

A summary of the findings related to quarrying and processing are:

- Some production and processing factors influence the bowing and deterioration pattern of marble cladding. The various factors depend to a large degree on the intrinsic properties of the marble itself.

- Even though various quarrying methods may give various impacts on the extracted rocks, it is very difficult to explain the different behavior in marble cladding as a result of the quarrying methods.

- There is no indication that diamond wire sawing introduces stresses within the rock material that may enhance the rock's bowing susceptibility. A marked stress relief may be experienced during diamond wire sawing, and not an introduction of stresses (or stress concentrations) as suggested in the literature.

- A relationship between the rock fabric on the one hand and bowing and expansion (and strength), on the other hand, has been found for some marble types. The cutting direction may therefore have an effect on the bowing and expansion potentials if the fabric of the marble is strongly anisotropic. However, it is most important to point out that marble types that have been found unsuitable for outdoor cladding should not be recommended regardless of extraction and processing directions. The decrease in strength may be equally high in such panels although in another direction and may therefore probably constitute an equally high a risk. In addition, it is, in most cases, not economically justifiable to experiment with different blocks in the natural stone industry.

- No conclusive answer can be given as regards the degree and speed of deterioration as a function of panel sizes. But thickness has been found to influence the bowing and deterioration of marble. A thick slab of unsuitable marble will bow eventually, but takes a longer time than a thin slab of the same marble. However, there is no safe thickness of slabs above which bowing will not occur. For a marble with favorable rock and mineral properties, the behavior is less dependent on thickness.

- Sawing, honing, and bush-hammering may cause slabs to bow during processing, typically towards the worked face. It has been verified that different marbles respond differently and that there is a relationship between the behavior during processing and the mechanical properties of the marble. Less stiff marbles with hysteresis in the stress/strain curve during unloading seem to be the most vulnerable. There is also a tendency for such marbles to be more prone to bowing as a result of stresses induced into the material from external factors like temperature and humidity gradients.

One of the most important findings in the project is the development of the possibility to quantify the microstructure of suitable calcitic marble types for cladding purposes. Adjacent grain analysis (AGA) is a quick and simple way of assessing whether a marble is likely to be suitable or not. AGA is a combination of grain size analysis and grain shape analysis. It will not quantify the magnitude of bowing or the strength loss that will occur over the years. But it will give a reliable basis for the decision whether it is justifiable to make more analyses, e.g., the laboratory bow-test, the wet-expansion strength tests, frost resistance testing, etc. Thus far, we have only been able to validate the method for calcitic marbles.

A lot of tests have been carried out trying to find out the potential relationship between lattice preferred orientation and bowing, and a clear correlation has been established. However, the influence on the magnitude of bowing is quite low for the marble types with a clear orientation. The difference is actually lower than the precision of the test method, but as it is systematic it cannot be ignored.

A huge number of other tests have been carried out, such as water absorption, capillary suction, flexural strength, breaking load energy, frost resistance, ultrasonic pulse velocity, long-term bending, heat 


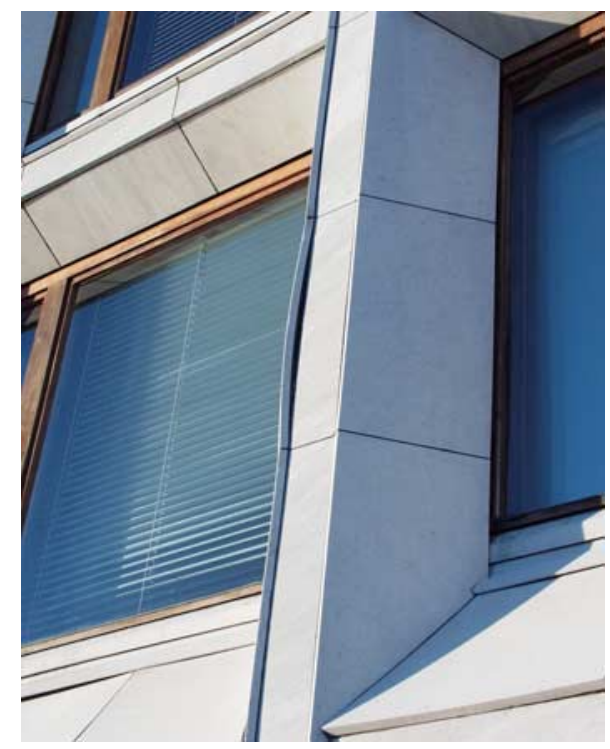

FIG. 5-The same marble can display different bowing patterns on the same building. Horizontal panels are concave and the vertical ones are convex.

capacity, heat conductivity and specific heat. One of the first important findings was the absolute necessity to dry marble and limestone samples at lower temperatures than those normally specified. Most standards specify the conditioning of stone samples to be done at $70^{\circ} \mathrm{C}$. TEAM has observed a significant reduction in strength at considerably lower temperatures. In order to minimize the damage of the test specimens before testing we therefore recommend drying at only $40^{\circ} \mathrm{C}$ for one week. This procedure has been used throughout the project.

Many of the results from these tests have contributed to the verification or refuting of the numerous pre-existing hypotheses. The possibility to compare a result obtained in the laboratory with that observed on a building or at the field exposure sites has been extremely valuable. Many results and relationships obtained in the laboratory cannot be proven to be consistent with observations in the field simply because of the complex nature of the problem, with several influencing factors acting at the same time. The same marble has been observed to bow in both convex and concave directions on the same façade and in very nearby position (Fig. 5). In places where the temperature variations are less extreme, parameters such as fabric may play a more pronounced role. On the south-, east- and west-facing sides of the building, where the temperature generally is the highest, temperature is by far the single most important influencing factor.

One of the main objectives of the project was to try to determine the mechanism for the bowing. However, even though a lot of progress has been made we feel that there is still some work left before we can give a full explanation of the mechanism. However, this additional work may not be economically justifiable from an industrial point of view, particularly since TEAM has developed a test method that correlates very well with the performance of marble cladding. It is easy to say that granular de-cohesion is causing the expansion and the bowing. However, we are still unsure as to why this phenomena does not take place in all marble types and why it is more often found in calcitic than dolomitic marble. The differential expansion in different crystal lattice orientation is a property that marble shares with many other rock types and cannot explain the phenomena by itself, although it is seen as an important contributing factor. Note that one bowing granodiorite has actually been found in Ljubljana, Slovenia. However, the reason for this bowing is not yet elucidated.

A crucial parameter is the complexity of the grain boundaries and the grain size distribution of mineral grains in the rock (Fig. 6). This provides different bonding strength between the mineral grains due to the complexity of the arrangement of the grain boundaries in combination with the crystal structure. The irregular grain structure that all marble types suitable for outdoor cladding have in common is the product of the metamorphism that turned limestone into a marble, combined with a dynamic recrystallization event. This type of event or metamorphism will create a more or less irregular microstructure with complex grain boundaries and a wide span of grain sizes and a crystal lattice that may include defects.

This structure gives a stronger grain boundary bonding through a mechanically stronger contact (com- 


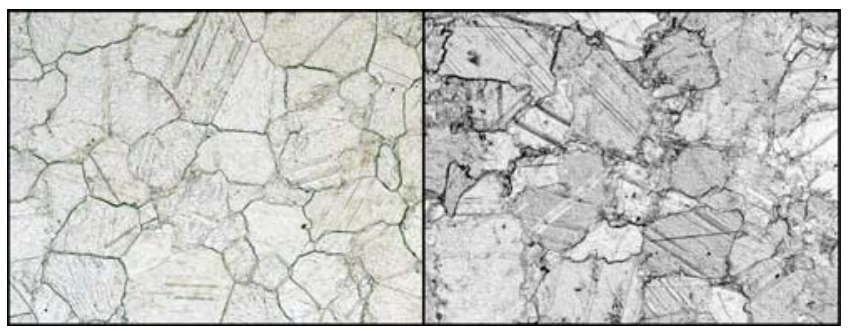

FIG. 6-The favorable microtexture of the marble to the right is caused by complex grain boundaries in combination with a range of different sizes of the grains. The marble to the left is prone to bowing due its quite simple structure with, more or less, mono-sized grains and straight grain boundaries [17,18]. The image corresponds to an area of 1.3 by $1.0 \mathrm{~mm}^{2}$.

plex grain boundaries) and a larger contact area, with more bonds between individual grains, through a larger surface area compared to the "ideal" regular hexagonal crystals. The type of mineral grain/crystal with complex shapes and lattice defects, mentioned above, is more prone to a change through redistributing individual atoms than a defect-free ideally-shaped hexagonal grains/crystal. This is due to the fact that such crystals have a higher inner energy, due to the strain energy, compared to ideally shaped ones. We may look on these defects as internal stresses built up during a dynamic recrystallization. Stresses that want to be released can do so without primarily affecting the grain boundaries. The triggering event can be exposure to the elevated temperature and moisture cycling on a façade. The ideally-shaped crystals don't have the same ability (or willingness) to rearrange atoms within the lattice and are therefore primarily reduced to movements along the grain boundaries causing granular de-cohesion. Furthermore, crack propagation as well as expansion and coalescence of voids can take place more easily in a structure with straight grain boundaries. The hypothesis described above is logical from a mineralogical point of view but should still be verified by laboratory testing on a nanoscale.

The influence of the water is also not totally clear but we know that stresses are built up both during the wetting and drying processes and we know that most marble types with a bowing potential have more open grain boundaries compared to the nonbowing types (Fig. 7). This enhances the ingress of water and larger capillary forces to act on the micro-scale for the unsuitable marble types, both during wetting and drying. Furthermore, the energy needed for crack initiation and propagation is lower in a wet rock when compared to a dry one. The reason for this is that the energy increase is higher when a solid-solid contact is replaced with a solid-air contact compared to a solid water contact.

Once the microstructure is open it is also easier for more water to enter the stone, water that may cause frost damage during the winter time. In addition, the weathering through acid solutions from polluted rain is enhanced in an open structure.

The great complexity of the problem is the most likely reason for many of the misconceptions in previous projects. Tests on too few marble types, in combination with the lack of opportunities for validating the results in the field, have often resulted in erroneous or unsubstantiated conclusions.

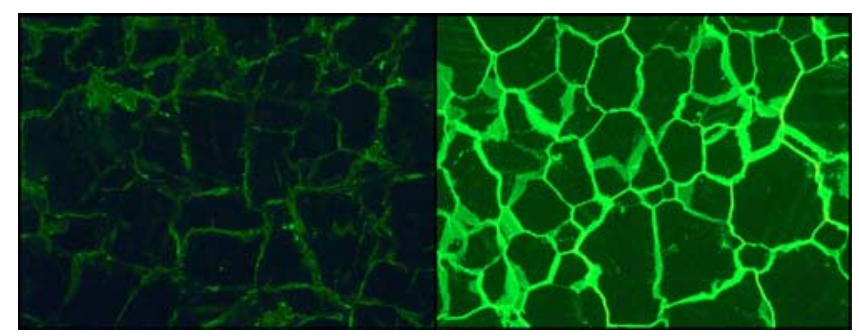

FIG. 7-Fluorescent microphoto of nonbowing marble to the left and a bowing one to the right. The marble to the right has a high proportion of cracks between the individual grains. The image corresponds to an area of 1.3 by $1.0 \mathrm{~mm}^{2}$. 


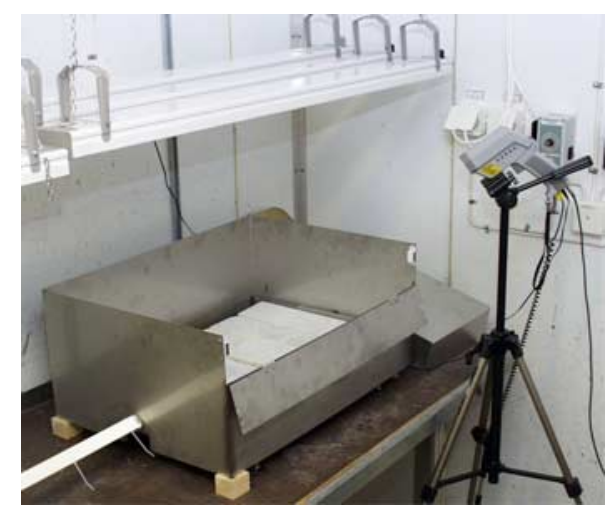

FIG. 8-Laboratory bow-test equipment for combining a wet underside with cyclic heating from above. Sample sizes are 30 by 100 by $400 \mathrm{~mm}$.

\section{Development of the Bow-test and the Wet-expansion Test-WP 6}

The work to develop test methods to determine the bowing potential and the temperature expansion in the wet condition crossed two work packages (WP 5 and 6). It was clear from an early stage of the project that a moisture gradient is needed to obtain bowing. This phenomenon had previously been observed on many flooring installations where marble tiles have bowed soon after the placement in a grout. However, this bowing is not permanent. The bowing we can observe on the buildings is to a large extent permanent and caused by elevated temperatures in combination with the moisture gradient. A laboratory test method was therefore developed to try to simulate these conditions. It is necessary in order to reproduce bowing in the laboratory to create the same conditions as on a façade (see Fig. 8). The detailed building inspections, together with the long-term monitoring and the literature study, have given the necessary information about the maximum temperature of a stone surface on a façade (at least in Europe). About $77^{\circ} \mathrm{C}\left(171^{\circ} \mathrm{F}\right)$ has been measured on a vertical panel of dark limestone and approximately $60^{\circ} \mathrm{C}\left(140^{\circ} \mathrm{F}\right)$ on a white Carrara marble [19]. Normal temperatures on a white marble on a sunny summer day is about $55^{\circ} \mathrm{C}$. It has also given information about the "ramp time," that is how fast the maximum temperature is reached and the time for the cooling of the panels. The resulting test method for bowing has produced results that correlate very well with the observations in the field. One important finding during the design of the method was the need to be able to repeat the temperature (T) cycle in every test and to ensure equal "climatic" conditions for any test specimen regardless of marble type, color, etc. The only way to achieve this was by using a black reference in accordance with ISO 4892-1 (Plastics-Methods of exposure to laboratory light sources). Note that it is the climate that is controlled and not the temperature of the stone!

The second test method developed is an expansion test that correlates better with the observed performance in the field than currently available standard methods. People responsible for designing a building generally favor a very small joint between stone panels. This joint is called a "dilatation" joint and is used to allow for some movement between the individual panels without causing any breakage. The usual input to the design of such a joint has previously been the "thermal coefficient of expansion" in the dry condition. The problem is that building façades are not always dry and the expansion in the wet condition is generally significantly higher than in a dry condition (not only for marble and limestone). Thus we frequently see damages like that in Fig. 9. Bowing is also a differential expansion and the causes of the two phenomena are, therefore, directly linked. The information input for the expansion test and the bowing test from other parts of the project is thus similar. It has proved insufficient to merely condition test specimens in different relative humidity. The test is, therefore, based on water saturated samples (Fig. 10).

Both test methods were used in an inter-comparison trial in accordance with the requirements stated in ISO 5725:1994 [20]. The repeatability $(r)$ and reproducibility $(R)$ were calculated accordingly.

Bowing Test-It should be noted that the conditions were not identical in all laboratories and the test results therefore vary more than expected. Both the stones and the bowing method are very sensitive to differences in temperature and not all the laboratories had the possibility to install the black reference during the project time. Slightly different layouts of the equipment were also reflected in different test results. However, it is clear that all laboratories have been successful in discriminating between bowing 


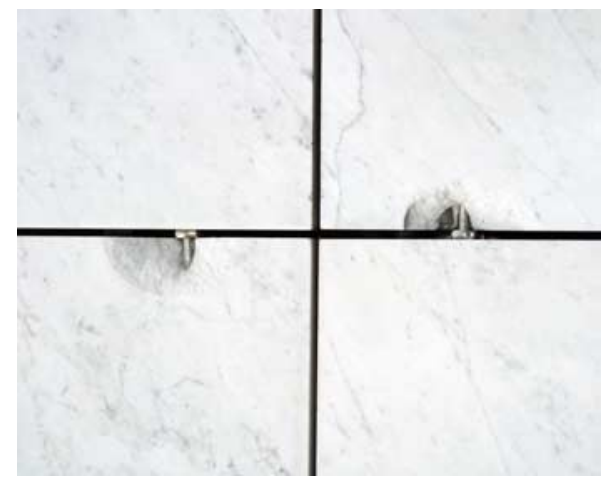

FIG. 9-Cracking at anchoring points due to excessive expansion in relation to the dimensions of "dilatation" joints.

and nonbowing marble through this test.

Note that there is, in general, one clear difference between the bowing direction observed in situ and results of the laboratory bow. In practice the bowing direction is almost "arbitrary," while in the bowing test, the specimens always bow towards the heat (i.e., upwards). This phenomenon is difficult to explain but has also been observed by other researchers [21-23].

Expansion-One major problem with the expansion test relates to the practicalities of carrying out the test. For example, despite many trials with different types of glue, some of the installed measuring points tend to detach from the stone surface during the expansion in hot water. It is therefore important to start with a large number of test specimens. This is a common problem shared with many other expansion methods, e.g., expansion of concrete and mortar. Similar to the bow-test, the expansion test can be further refined but it has already proved to be able to give clear guidance on the suitability of a marble (and limestone) type for cladding. In addition, it provides an important input to the dimensioning of the "dilatation" joints. Another important finding is that some marble and limestone types tend to show a continuously increasing expansion while others display a limited expansion.

Both test methods are complemented by the determination of flexural strength after the temperature cycling. This provides a clear indication of the potential strength decrease over time and so provides an important input to the prediction of the service life. However, it should be noted that if a more precise estimate of the service life is needed, it is necessary to know the temperature and temperature variations of

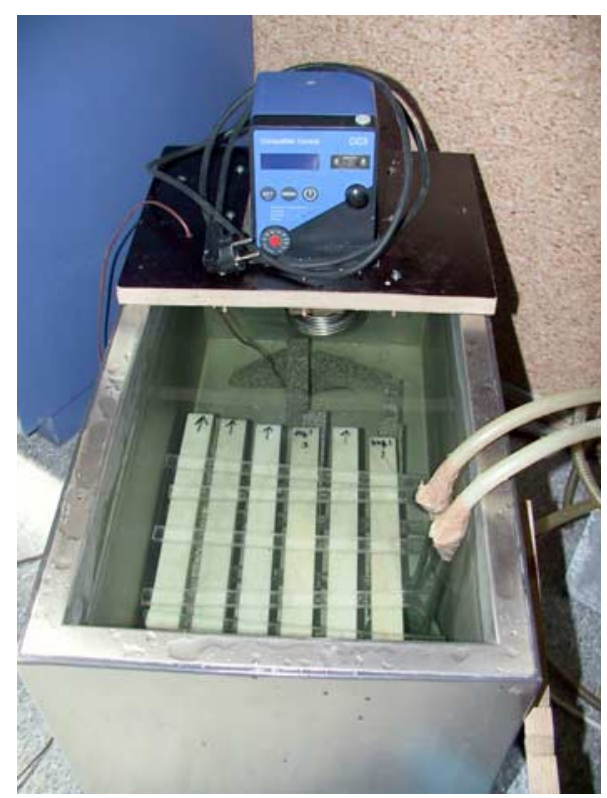

FIG. 10-Laboratory test for moisture and heat-induced expansion, providing relevant data for dimensioning of dilatation joints. Sample sizes are 30 by 30 by $200 \mathrm{~mm}$. 


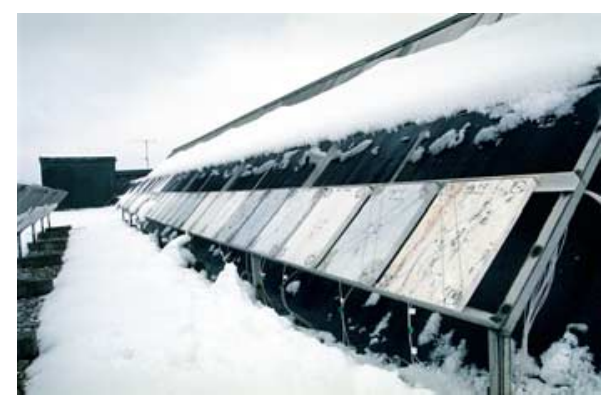

FIG. 11-Field exposure site in Ljubljana, Slovenia. Sample sizes are 30 by 400 by $500 \mathrm{~mm}$.

the stone surface on the actual locality of the building. If a bowing marble has been chosen it may also be necessary to determine the frost resistance of that stone before and after temperature cycling.

\section{Field Exposure and Possibilities to Prevent the Bowing or Decrease the Speed of the Aging-WP 7}

Five field exposure sites have been installed in Sweden, Poland, Slovenia (Fig. 11), Italy, and the U.K. and one in situ on the City Hall in Nyköping (E Sweden) [24]. The test sites have provided essential information about the behavior of different marble types, and the influence of thickness and of chemical treatments, e.g., surface coatings and impregnation.

It has been concluded that all marbles, both calcitic and dolomitic, showed a degree of bowing that could be measured under field conditions; however, the magnitudes differ greatly. Comparable bowing was observed in all climatic zones of the participating countries with Itq2 (Gioia from Carrara) panels displaying the highest bowing and deterioration potential after one year's exposure at every field exposure site. Itq2 was the most sensitive marble but other types such as the Thassos marble, from Greece, showed slight bowing and especially cracking independently of the climate. It is essential to point out the substantial difference between bowing magnitude of the same samples measured at field conditions and after drying indoors (used as reference measurements four times a year). All results from in situ measurements gave higher bowing compared to measurements on dried samples. In some cases, marble panels showing bowing when measured on the field exposure sites showed no signs of bowing after drying in indoor conditions. This indicates that no permanent bowing could be observed for these panels. Therefore, it is recommended that bowing measurements taken outdoors should be taken when the temperature variations are as small as possible (summer and winter) and that the measurements are repeated on a number of occasions.

Analyses of how thickness and impregnation influence the bowing properties were performed on one type of fresh marble, Itq2, and on the old panels on the façade in Nyköping. The analysis of variance indicates that bowing depends on the thickness and impregnation. The highest bowing was observed for the 20-mm (3/4-in.) thick panels and lowest for the $30 \mathrm{~mm}$ (1 3/16 in.) impregnated thick panels. Both impregnation agents were shown to have an inhibiting effect on bowing process after one year of exposure. However, after three years of exposure it was clear that only the microcrystalline wax (AGS) was preventing bowing. Impregnation with a hydrophobic treatment decreased the bowing tendency of the fresh panels. The results from the field exposure were comparable to results from the laboratory experiment on the old panels from the Nyköping. The AGS impregnated samples showed small or no bowing at all. This effect could not be observed for the GS impregnated samples. No aesthetic change could be observed as a result of the impregnation process. Hydrophobic treatments had an inhibiting effect on the bowing and could be recommended as a remedial action for damaged panels, thought not as a final solution. It is important that each case is investigated independently.

\section{Guidelines for Production and Product Control-WP 8}

Guidelines for the production of panels and product control have been drafted. They are primarily directed towards the producers and suppliers, but also to designers. The importance of choosing a technically suitable marble for outdoor claddings is strongly emphasized. If a bowing marble is chosen or one that rapidly will lose strength, the consequences are considerable-for example in terms of increased maintenance costs due to the fact that such a marble will quickly develop an open micro-structure, especially in 
the surface, that is more susceptible for soiling. Removal of graffiti will be more difficult and, of course, the risk of failure due to loss of strength will make it necessary to monitor the changes and finally change part, or all, of the façade before the risks of panel failure becomes unacceptable. Technically acceptable properties should therefore have very high priority when choosing a marble type for a building project; whereas today aesthetical properties are often considered as being of greatest importance even though the aesthetic properties will change rapidly for a nonsuitable marble as it deteriorates.

The recommendations to the producers are to provide a geological map of their quarry and request a petrographical analysis including the AGA for all areas identified as significantly different. They should then carry out the laboratory bow-test and the wet expansion test to establish a correlation between those parameters and the petrography. By using nondestructive tests it should be possible to identify major changes at the rough block stage of production and thereby avoiding unsuitable material entering the processing stage. A detailed instruction for marking and identification of material at all stages is also strongly recommended for the sake of traceability and feed back to the production company. The sampling of test materials is very critical for any project. Detailed sampling and sample marking instructions have to be used for any sampling. Our findings, guidelines for sampling, have been reported to CEN TC 246 Natural Stone. Guidelines have also been given to designers and producers/suppliers to ensure a proper selection of suitable marble and limestone for outdoor cladding and to ensure production with a homogeneous and acceptable quality, respectively.

\section{Dissemination-WP 9}

A number of presentations and proceedings have been prepared for various conferences $[19,21,24]$. In addition, publications in scientific magazines and parts of doctoral theses are also results of the project. See the TEAM homepage for more information and download possibilities of brochure and technical reports (with test results), test methods, etc.: www.sp.se/building/team.

\section{Conclusions}

The main findings and conclusions are given below:

- Bowing is a worldwide phenomenon not confined to one type of marble or one type of climate, e.g., frost action is not necessary for this phenomenon to occur.

- The driving force of the degradation is the combination of elevated temperature in the presence of a moisture gradient. The latter is a crucial ingredient!

- Every marble is unique and has a unique response to these climatic stresses with its own degradation curve (i.e., loss of strength versus time). The acceleration factor of a laboratory bow-test is therefore different for different marble types.

- The most crucial intrinsic parameters are the degree of complexity of the grain boundaries combined with the grain size distribution of mineral grains in the rock. This provides different bonding strength between the mineral grains due to the complexity of the arrangement of the grain boundary and in combination with the crystal structure. The irregular grain structure that all marble, considered suitable for outdoor cladding, has in common is the product of the metamorphism that turned limestone into a marble combined with a dynamic recrystallization event. Weaker bonds will cause granular decohesion, "sugaring," of the marble and significant strength losses. Of the utmost importance is that this microstructure can be quantified. Limiting values can therefore be established.

- The laboratory test methods developed in TEAM enable a relevant evaluation of whether a marble is suitable for outdoor cladding or not and how to dimension dilatation joints for marble and limestone cladding. The bow-test can also be adapted and used for predicting the remaining service life of a specific marble on a particular building.

- One time in situ measurements of bowing amplitude, etc., are of little use due to large diurnal and seasonal variations. Repeated measurements therefore have to be carried out in order to enable a reliable risk assessment of a damaged façade.

- It is possible to inhibit or decrease the degradation of marble by coating the surface with a hydrophobic treatment. The effect is most pronounced on marble already exposed and it should not be used to support the selection of an unsuitable marble for a new building project. Whether or not this is a cost efficient solution has to be decided on a case by case basis. 
The TEAM project has given our knowledge of marble and limestone deterioration processes a significant push forward and we hope that our findings will contribute to an increase in the use of marble and limestone for cladding and thus help in regaining some of the trust lost in these materials in particular climates and countries.

\section{Acknowledgments}

We wish to acknowledge support by the European Commission, which has partly funded the TEAM project, contract No. G5RD-CT-2000-00233 under GROWTH Program "Competitive and Sustainable Growth, Expanding the Limits and Durability of Structural Material."

\section{References}

[1] NT Build 499 Cladding Panels, "Test for Bowing," Published by Nordtest, Tekniikantie 12, Espoo, Finland-www.nordtest.org, 2002.

[2] Erlin, B., "Contribution to a Better Understanding of the Mechanism Causing Dishing Failures of the Carrara Marble When Used for Outside Building Facades," ASTM STP 1394, ASTM Symposium on Dimension Stone Cladding: Design, Evaluation, Construction and Repair, New Orleans, Oct. 27, 1999, pp. 71-78.

[3] Suenson, E., Byggematerialer (Building Materials), 3rd ed., Natursten. Jul. Gjellerups Forlag, Copenhagen, 1942, pp. 36-38 and 126-139.

[4] Tschegg, K. E., Widhalm, C., and Eppensteiner, W., "Ursachen mangelnder formbeständigkeit von marmorplatten," Zeitschrift der Deutscher Geologischer Gescheltshaft, Vol. 150, No. 2, 1999, pp. 283-297.

[5] Vogt, J. H. L., "Norsk marmor (Norwegian marble)," Norges Geologiske Unders $\phi g$ gelse No. 22, 1897.

[6] "Developing long-term durability of marble façades," Mara Project, Final technical report 30.04.2001, unpublished. European Commission (Raphael program).

[7] Sage, J. D., "Thermal microfracturing of marble," Eng. Geol. of Ancient Works, Monuments and Historical Sites, 1988, pp. 1013-1018.

[8] Winkler, E. M., Stone in Architecture, Springer Verlag, 1994, 300+ pp.

[9] Royer-Carfagni, G., "Some Considerations on the Warping of Marble Facades: The Example of Alvar Aalto's Finland Hall in Helsinki," Constr. Build. Mater., Elsevier, Vol. 13, 1999, pp. 449-457.

[10] Bain, G. W., "Geological, Chemical and Physical Problems in the Marble Industry," American Institute of Mining and Metallurgical Engineers, Technical Publication No. 1261, 1940, 16 pp.

[11] Ihalainen, P., Uusinoka, R. P. J., "Comparison of Weathering Resistance of Some Building Stones Based on Treatments Simulating Different External Conditions," Proceedings 7th International Congress of the International Association of Engineering Geology, Sep. 5-9, 1994, Lisboa, Portugal.

[12] Barsotelli, M., Fratini, F., Giorgetti, G., Manganelli Del Fá, G., and Molli, G., "Microfabric and Alteration in Carrara Marble: A Preliminary Study," Science and Technology for Cultural Heritage, Vol. 7, No. 2, 1998, pp. 115-126.

[13] Cantisani, E., Canova, R., Fratini, F., Manganelli Del Fá, C., Mazzuoli, R., and Molli, G., "Relationship Between Microstructure and Physical Properties of White Apuan Marbles: Inferences on Weathering Durability," Periodico di Mineralogia, Vol. 69, No. 33, 2000, pp. 257-268.

[14] Grelk, B., Christiansen, C., Malaga, K., and Schouenborg, B., "Durability of Marble Cladding-A Comprehensive Literature Review," J. ASTM Int., Vol. 4, 2007.

[15] TEAM, "Testing and Assessment of Marble and Limestone," Final Technical Report, Oct. 2005. EC-Project: TEAM-G5RD-CT-2000-00233.

[16] TEAM, "Building Inspections," Oct. 2001, EC-Project: TEAM-G5RD-CT-2000-00233. Publication No. 2.

[17] Alnæs, L., Koch, A., Schouenborg, B., Åkesson, U., and Moen, K., "Influence of the Macro- and Microstructure on the Durability of Facade Material," Proceedings of the International Conference on Dimension Stone 2004, 14-17 June, Prague, Czech Republic.

[18] Åkesson, U., "Microstructures in Granites and Marbles in Relation to Their Durability as a Construction Material," Göteborg University, Earth Science Centre, Thesis for doctoral degree, A 95, 2004. 
[19] Perrier, R., "Measure de la décohésion thermique des marbres par l'attenuation des vibrations en flexion," TechniPIERRE 96-Problematique des Pierres dans la Restauration des Monuments, 1996.

[20] ISO 5725-94, Precision of Test Methods-Determination of Repeatability and Reproducibility for a Standard Test Method by Inter-laboratory Tests.

[21] Yates, T., Brundin, J. A., Goltermann, P., and Grelk, B., "Observations from the Inspection of Marble Cladding in Europe," Proceedings of the International Conference on Dimension Stone 2004, 14-17 June, Prague, Czech Republic.

[22] Karhapää, E., Koskinen, P., Pyy, H., Silvennoinen, K., and Sipari, P., "Weather Resistance Tests with Carrara Type White Marble," VTT, Building Technology, Concrete and Minerals Technology, Internal Report 2, RTE5-IR-2, 1994.

[23] Koch, A. and Siegesmund, S., "Bowing of Marble Panels: On-site Damage Analysis from the Oeconomicum Building at Göttingen (Germany)," Natural Stone, Weathering Phenomena, Conservation Strategies and Case Studies, Geological Society Special Publication No. 205, London 2002.

[24] Malaga-Starzec, K., Schouenborg, B., Alnaes, L., Bellopede, R., and Brundin, J.-A., "Field Exposure Sites and Accelerated Laboratory Test of Marble Panels," Proceedings of the International Conference on Dimension Stone 2004, 14-17 June, Prague, Czech Republic. 